\title{
The Significance and Application of Foliation Intersection/Inflection Axes (FIA) within Porphyroblasts: A review
}

\author{
Meng-Wan Yeh ${ }^{1, *}$
}

(Manuscript received 1 June 2003, in final form 17 September 2003)

\begin{abstract}
An increasing number of structural and metamorphic studies throughout the past sixty years have shown the importance of using porphyroblast microstructures to gain further understanding of deformation and metamorphic history and mechanisms. A recent very significant advance has been the development of techniques for the measurement of Foliation Intersection/Inflection Axes (FIAs) preserved within porphyroblasts. FIAs provide a quantitative method of microstructural analysis that enables the direct linkage and integration of the deformation, metamorphic and tectonic history. The FIA technique determines the orientation of or the axis of curvature of a foliation effected by an overprinting event, or the intersection lineation between successive foliations, preserved as inclusion trails within porphyroblasts. Because the axis is determined completely independent of the model of formation of these included foliations, it allows such models to be thoroughly tested. The method involves three-dimensional examination of microstructures within porphyroblasts in several vertically orientated thin sections that fan around the compass and which have been cut from spatially orientated samples. FIA measurements allow reconstruction, correlation and dating of regional and large-scale deformation and metamorphic histories. Such reconstructions of the tectonic evolution had been conducted in several orogenies around the world. New insights include (1) the intimate control of deformation partitioning on metamorphic reactions, (2) a possible technique for determining the direction of relative plate motion within ancient orogens, and (3) the role of rotation versus non-rotation of porphyroblasts relative to geographical coordinates during deformation have also been raised.
\end{abstract}

(Key words: FIA, Microstructure, Foliation, Porphyroblast)

\footnotetext{
${ }^{1}$ Department of Earth Sciences, National Taiwan Normal University, Taipei, Taiwan, ROC

${ }^{*}$ Corresponding author address: Dr. Meng-Wan Yeh, Department of Earth Sciences, National Taiwan Normal University, Taipei, Taiwan, ROC; E-mail: porphyroblast@yam.com
} 


\section{INTRODUCTION}

The correlation of structure, microstructure and metamorphic assemblages is of fundamental importance to an understanding of the tectonic history of metamorphic belts as it provides constraints on the relative timing of deformation and metamorphism. Porphyroblasts in metamorphic rocks commonly record long local histories of foliation development as inclusion trails where the earlier history has been destroyed in the matrix by prograde metamorphism, continued deformation or matrix coarsening processes (e.g., Bell and Johnson 1989; Davis 1995; Powell and Vernon 1979; Rosenfeld et al. 1988). Although these inclusion trails ( $\mathrm{S}_{i}$ ) commonly have complex geometries, they attract broad interest as the microstructures preserve unique structural markers, and can be utilized to evaluate deformation and metamorphic processes, quantifying a wide variety of orogenic parameters such as: syn-orogenic bulk shortening directions (Bell et al. 1998; Rosenfeld 1968; Yeh 2002), fold mechanisms (Bell and Hickey 1997; Hickey and Bell 1999; Yeh 2002), and tracking foliation development during progressively changing metamorphic conditions (Williams 1994; Bell et al. 2003). Furthermore, their relationships with the surrounding matrix have been used extensively to reconstruct the deformation history and infer the timing of metamorphic mineral growth relative to deformation (e.g., Johnson 1990; Bell et al. 1992a, b, c; Passchier et al. 1992; Forde and Bell 1993; Johnson 1993a, b; Johnson and Williams 1998; Williams and Jiang 1999; Stallard and Hickey 2001).

Despite the significance of porphyroblast microstructures, correlation between microstructural features, deformation and metamorphic events, as well as tectonic movements over a large-scale geological terrain was not previously possible. In an attempt to resolve this problem, Hayward (1990) proposed a microstructural measuring technique that allowed routine measurement of the axes of curvature or intersection of foliations preserved as inclusion trails within porphyroblasts. The previous method proposed by Rosenfeld (1970) was complex and had not been used by others. These axes have become know as foliation inflexion/intersection axes within porphyroblasts or FIAs (Bell et al. 1995, 1998, 2003). This paper provides a brief summery of this relatively new technique and reviews its application and significance.

\section{FIA DETERMINATION AND MEASUREMENT METHODS}

The curved inclusion trails preserved within porphyroblasts are remains of pre-existing matrix foliations that have been overgrown by continuous deformation and metamorphism. Many terms have been used to describe them such as rotation axes, spiral axes, relative rotation axes, fold axes, microfold axes, and foliation intersection/inflection axes (abbreviated FIA henceforth; Figs. 1a and 2a). FIA as defined above is utilized in this paper as this term does not have specific implications on the mechanism of formation of curved or intersecting foliations defined by inclusion trails within porphyroblasts. FIA trends are determined by recording the asymmetry switch of equivalent inclusion trail curvatures when viewed from the same direction in a series of differently striking vertical thin sections of an oriented sample that fan about the compass as shown in (Figs. 1a and 2b). Figure 1a illustrates a sample containing simple spiral inclusion trails within garnet porphyroblasts. The geometry observed ( $\mathrm{S}$ 
or Z; clockwise or anticlockwise) within porphyroblasts represents the intersection of the 3-D shape of the included foliations with the differently oriented thin sections. The inclusion trail asymmetry forms an open "z" shape (anticlockwise) while looking towards north for the $70^{\circ}$ striking section. Each vertical section is viewed in the same orientation around the compass. The open " $\mathrm{z}$ " shaped inclusion trail switches to an open "s" shape (clockwise) asymmetry at the $140^{\circ}$ striking section where the FIA trend is crossed. Thus, the FIA trend is located between the sections with two opposing inclusion trail geometries (Hayward 1990; Bell et al. $1995 ; 1998)$. The FIA trend is bi-directional $\left(110^{\circ}=290^{\circ}\right)$ if the plunge has not been determined.

The FIA plunges are measured from a series of thin sections striking parallel to the FIA trend with various dips varying from $0^{\circ}$ to $90^{\circ}$ (Fig. 1b). Similar to determination of FIA trends, the asymmetry switch of inclusion trails looking in the same direction defines the orientation of the plunge (Fig. 1b). Porphyroblasts with multiple growth episodes preserve more complex inclusion trails with multiple FIAs (Fig. 2). The succession of these differently trending FIAs preserved from core to median to rim of a porphyroblast within one sample provides a tool for determining the relative timing of successive FIAs (Fig. 2b).

FIA trend determination can be difficult for samples with complex histories preserved in their inclusion trails. Yeh (2002) showed that the asymmetrical approach to FIA determination was not sufficient for samples preserving a complex deformation history but containing relatively simple (straight to slightly curved) inclusion trails. In that case, the asymmetries of the inclusion trails from vertical to horizontal and vice versa were employed. For rocks with multiple relatively coaxial crenulations or simple straight trails, Aerden (2003) developed the "FitPitch" computer program for FIA determination. Instead of observing asymmetries of the inclusion trails within porphyroblasts, the pitch or strike angles of the inclusion trails are measured and plotted to determine the orientation (best-fit plane) of the foliations defined by these inclusion trails. Intersection-lines (FIAs) are determined by fitting the theoretical intersectionlines of a single model-plane, or a combination of two or three model-planes. The advantage of this approach is that both trend and plunge of the FIA are measured in one step, and the data can be easily reproduced regardless of observers' background and experience.

\section{COMPLICATIONS AND SPREAD OF FIA TRENDS}

Previous studies have shown that the FIA trend in individual porphyroblasts from one single sample or between samples with similar FIA trends range slightly in orientation (Hayward 1990; Johnson 1993a; Bell et al. 1995). This results from the anastomosing of foliations around euhedral porphyroblast crystal faces. It also results from the natural anastomosing of foliations which is an inherent result of deformation involving a bulk shortening component (Bell 1981). Bell and Hickey (1997) determined the total accumulated error from using a compass to orient and reorient the sample in determining the trend of FIA to be $\pm 8^{\circ}$. This involves $\pm 1^{\circ}$ from the precision error of compass (Cocla) used to mark the orientation mark on samples in the field, another $\pm 1^{\circ}$ from repositioning of compass relative to the orientation mark on rock faces back in the laboratory, $\pm 2^{\circ}$ from the error in cutting the sample into horizontal slabs and marking north on them, and $\pm 2^{\circ}$ from the error in marking on and cutting thin section blocks from these 
a)

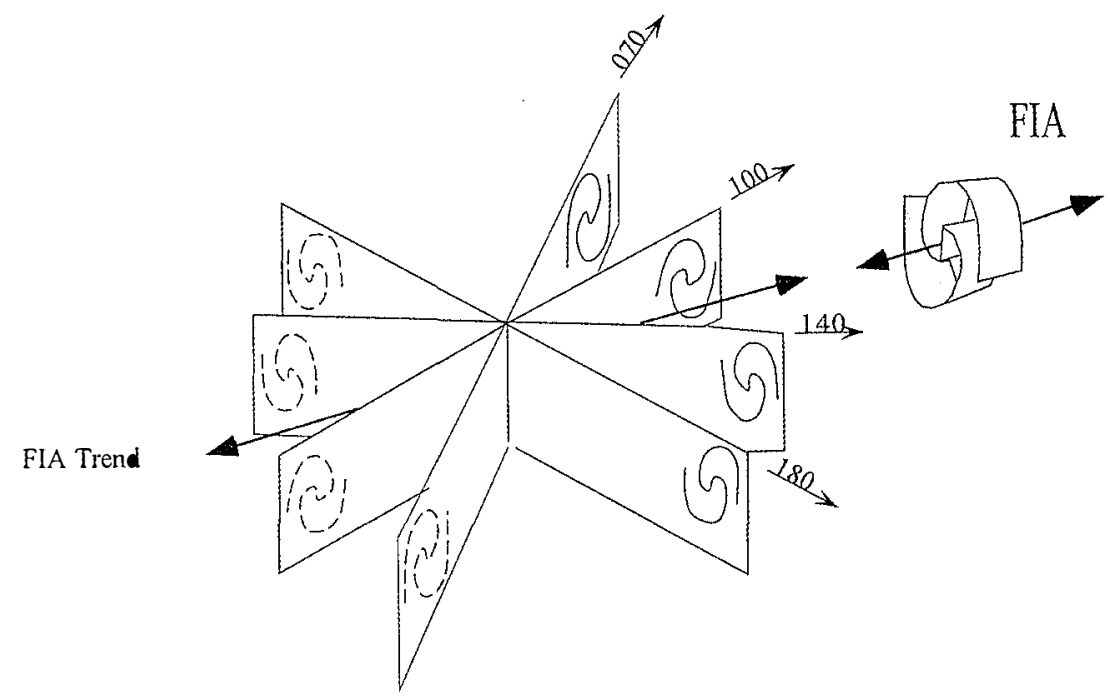

b)

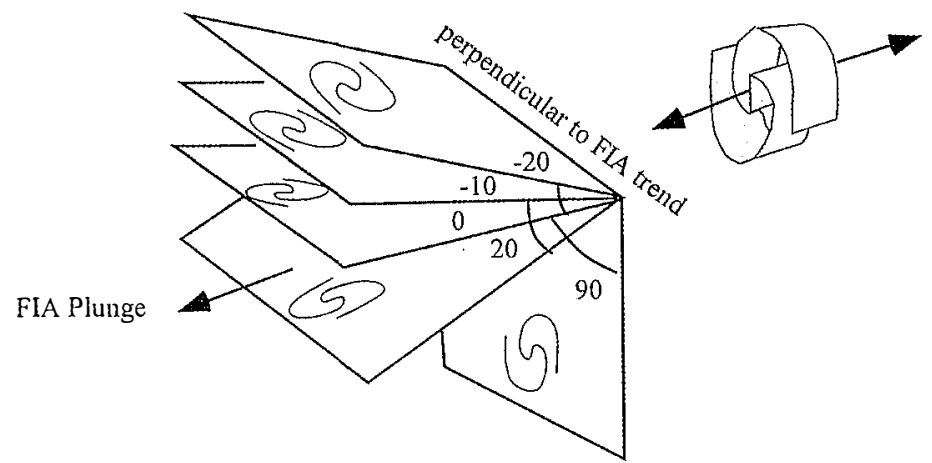

Fig. 1. 3-D sketches showing the method of using oriented thin sections to determine the FIA orientation. The asymmetry of inclusion trail curvature switches when viewed in the same direction on thin sections across a FIA. (a) Determination of FIA trends. (b) Determination of FIA plunges.

slabs. These errors are all random and all of the same order of magnitude, suggesting that the total accumulated error probably has a normal distribution. In multi-FIA samples (samples that contain more than one FIA trend each), errors between relative trends of FIAs are only a function of the last two stages of sample preparation (cutting of slabs and thin section blocks from slabs) as they are obtained from one sample, and they should have a relative precision of $\pm 4^{\circ}$ (Bell and Hickey 1997). Stallard (1999) and Stallard and Hickey (2001) estimated the variation in a FIA set ranges from $\pm 15^{\circ}$ to $20^{\circ}$ (minimum) to $50^{\circ}-60^{\circ}$ (maximum) from the effects of anastomosing foliations. Consequently, determination of FIAs requires interpreting 2-D sections of usually complex inclusion trails, it is common to find both anticlockwise and clockwise asymmetries within sections oriented close to the FIA. Thus, the FIA for a sample 
a)

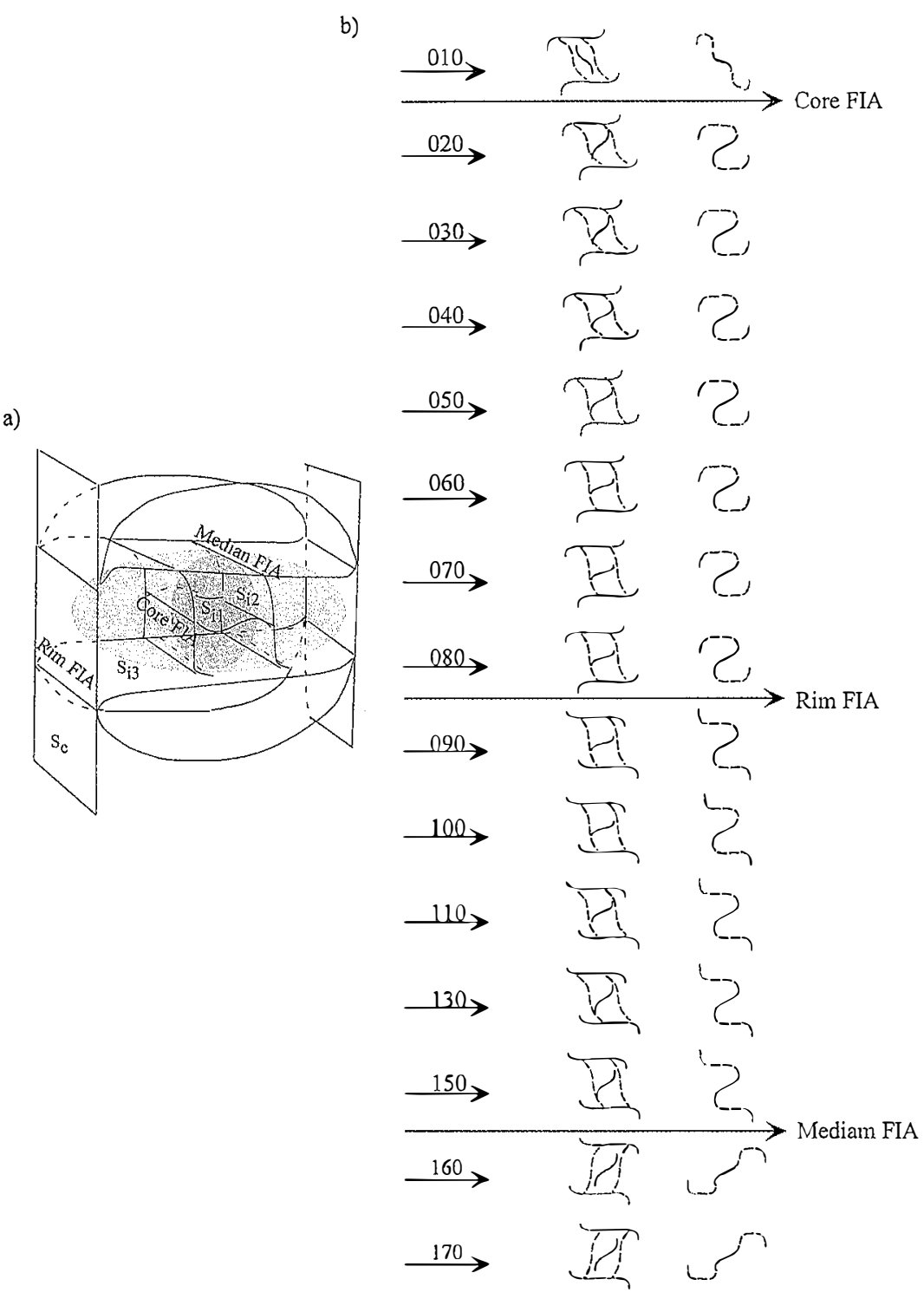

Fig. 2. Schematic diagrams showing the location of FIA relative to foliations within a porphyroblast with multiple growth episodes (modified from Bell et al. 1997, 1998). (a) 3-D cross section sketch of an euhedral porphyroblast with 3 internal foliations ( $\mathrm{Si} 1, \mathrm{Si} 2$ and $\mathrm{Si} 3$ )and one matrix foliation (Se). The intersection lineation between these foliations are FIAs. (b) sketches of inclusion trail patterns correlation to (a) from vertical thin sections with various strikes. 3 FIAs of $15^{\circ}$ (core), $155^{\circ}$ (mediam) and $85^{\circ}$ (rim) with temporal correlation can be distinguished. Black solid line indicates the core inclusion trail, black dashed line for the median inclusion trail, and gray line for the rim inclusion trail. 
can be defined as lying at the midpoint between the sections where the majority of inclusion trail asymmetries switch asymmetry. Other than anastomosing of foliations, Stallard (1999) further suggested three contributing factors for the variety of geometries in different sections: (1) the relative position of the section with respect to the center of the porphyroblast (Fig. 3) and (2) the angle of the section respect to the axis of relative rotation of the inclusion trails. Consequently, variably oriented thin sections from a single porphyroblast can potentially produce apparently dissimilar and unrelated inclusion trail geometries due to increasing variation in the pitch of an inclusion trail trace with increasing distance from the centre of porphyroblast. Furthermore, the inclusion trails preserved within the cores of porphyroblasts are not evident unless the section intersects the centre of the porphyroblast (Fig. 3). This reflects the spread in FIA orientation within and between porphyroblasts in the sample. Although extensive discussions on the spread of FIA were conducted by numerous researchers, non had provided any solutions on resolving this complication. One can reduces the potential errors by increasing the sampling population by making more oriented thin sections, however, this still involves correlation between different porphyrioblasts. New techniques utilizing computed X-ray tomography for FIA determination is currently conducted by the SAMRI research group of the school of Earth Sciences in the James Cook University, Australia. Although at its early developing stage, this new technique allows the trails preserved within one single porphyroblast to be viewed in three dimensions. With the 3-D images, FIAs can be determined from one porphyroblast instead of correlating numerous porphyroblasts within and between thin sections, which would be the potential error. Most importantly, this technique allows evaluation on (1) the variation of FIAs between different porphyroblasts within one sample, and (2) the accuracy of FIA trends obtained by examining the inclusion trail geometries from oriented thin sections (Huddlestone-Holmes, pers com.).

\section{GROUPING AND TEMPORAL CORRELATIONOF FIA SETS}

The most prominent feature of the FIA data is the non-random multimodal nature of FIA trends shown by rose diagrams of FIA data (Fig. 4a). Bell et al. (1998) first applied the Watson's $\mathrm{U}^{2}$ test (Freedman 1981) modified for grouped axial data by Upton and Fingleton (1989) to determine the significance of the multimodal nature of FIA data. Bell et al. (1998) and Yeh (2002) both showed that FIA data under different groupings measured from Spring Hill, Connecticut, and eastern Maryland Piedmont are statistically significant, and the multimodal FIA data are not a random population. Thus, polymodal FIA trends are meaningful and can be separated into groups (FIA sets). However, the fluctuations seen from rose diagrams (Figs. 4a, b) do not allow easy interpretation of meaningful peaks or modes as the spread of a FIA within one sample may range up to $20^{\circ}$ or more (Stallard 1999; Stallard and Hickey 2001). By smoothing the FIA data with moving averages (King 1994), Yeh (2002) attempted to discern modes of FIA data more objectively than by a visual separation of the rose diagram (Fig. 4c). Furthermore, microstructural relationships between $\mathrm{S}_{\mathrm{i}}$ and $\mathrm{S}_{\mathrm{e}}$, and the temporal succession from core to median to rim must also be complied when determining the different FIA sets. Systematic correlation between inclusion trail curvatures within a sample for determining the 
a)

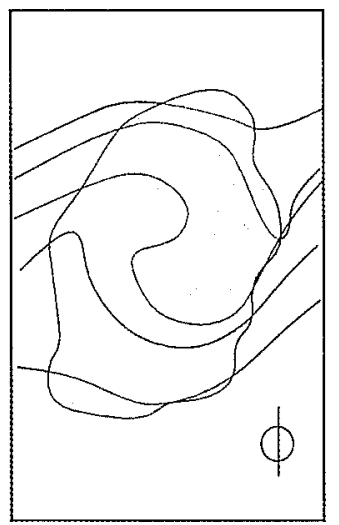

c)

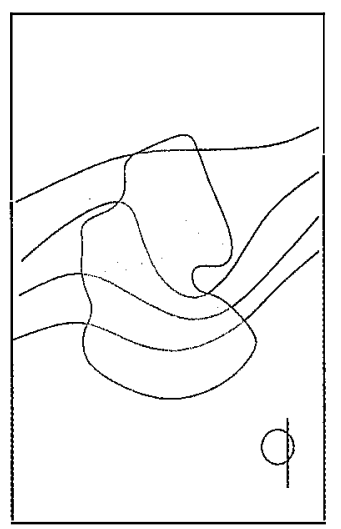

b)

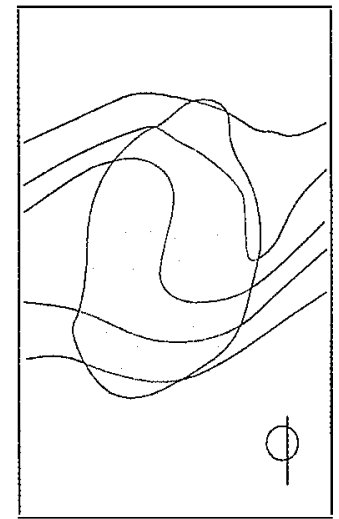

d)

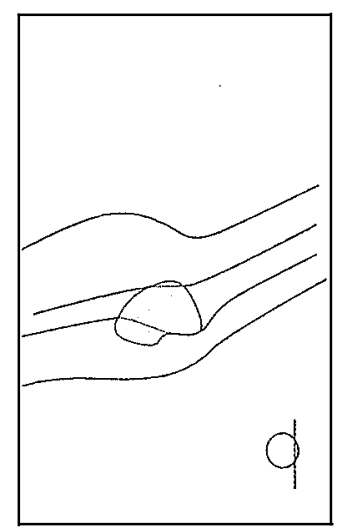

Fig. 3. Diagrams illustrating the influence of cut effects on 2-D inclusion trail geometries produced from a single 3-D geometry while a porphyroblast is cut at increasing distance from the porphyroblast center from (a) to (d), modified from Johnson, (1944).

FIA orientation, and correlating FIAs between samples to distinguish temporally-related sets are two major components for application of FIA techniques. The succession of differently trending FIAs preserved from core to median to rim of a porphyroblast within one sample provides a tool for establishing relative timing (Table 1).

\section{APPLICATIONS OF FIA DATA}

\subsection{Porphyroblast Growth-timing Criteria}

Determining suitable timing correlation criteria for metamorphic rocks is very important if one is going to be able to resolve the tectonic development of a region. The timing of porphyroblast growth relative to surrounding foliations can be determined from their textural 
a)

b)
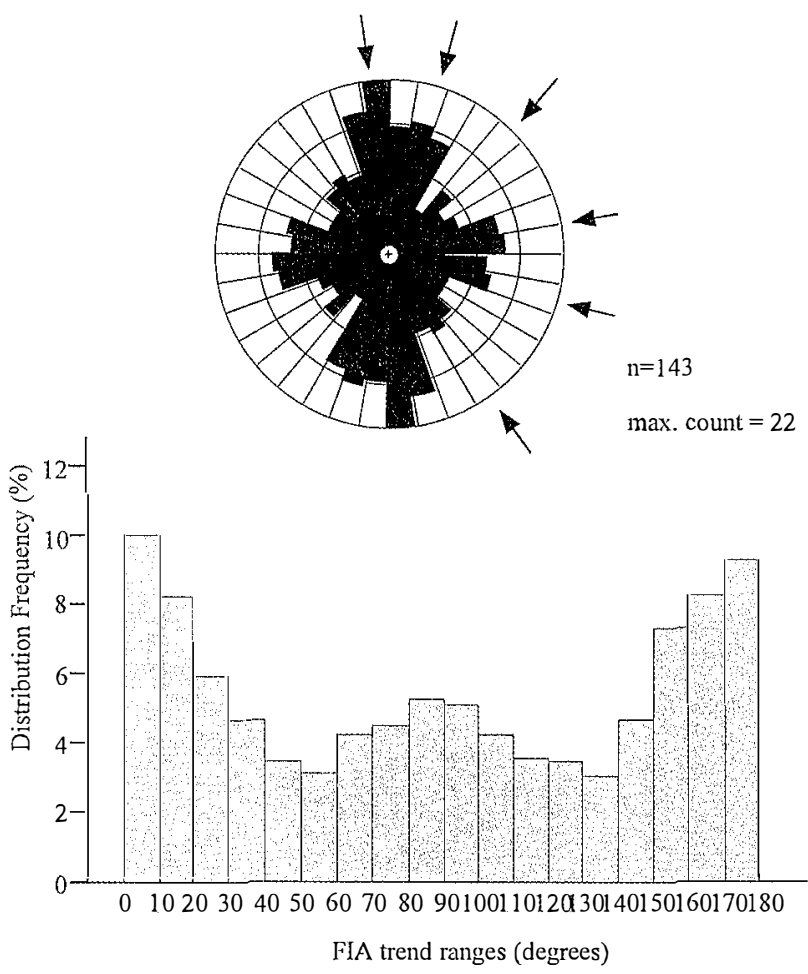

c)

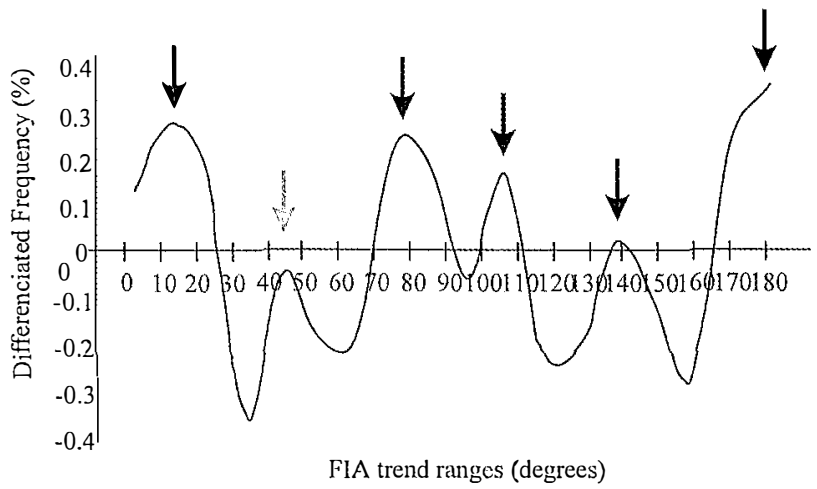

Fig. 4. Diagrams showing distribution of FIAs measured from garnet porphyroblasts around the Baltimore Gneiss Domes, Maryland, USA. (a) Equal area (radii $=$ square root of frequency) rose diagrams, with a $10^{\circ}$ class interval, North $\left(0^{\circ}\right)$ at top with arrows pointing to peaks of FIA sets. (b) FIA frequency distribution with $10^{\circ}$ class interval with undistinctable peaks and troughs. (c) Smoothed FIA frequency distribution by fractionated moving averages with the order $\mathrm{N}=5$. Five distinct peaks is indicated with black arrows. A undistinguished (below 0 ) peak between $40^{\circ}$ to $50^{\circ}$ is indicated with grey arrow. 
relationships and metamorphic assemblages. Such chronological sequencing is essential for understanding the pressure-temperature-deformation evolution and spatial relationships between deformation and metamorphism. However, microstructural studies using FIAs has shown that most porphyroblast growth predates the foliations now preserved in the matrix (Bell et al. 1998, 2003). The matrix foliation gets reworked during each successive deformation such that only the very youngest events are preserved. Bedding in polydeformed and metamorphosed rocks always has a deformation-generated foliation parallel to it (Bell et al. 2003). Wrapped into parallelism with bedding are all the remains of the earlier developed foliations. However, the porphyroblasts preserve this earlier developed foliation history and allow data on it to be extracted and dated using the FIAs (Bell and Welch 2002). This allows several periods of porphyroblast growth that predate the matrix foliation to be correlated and thus P-T paths to be extended way back into the early history of tectonism (Welch 2003). Yeh (2002) evaluated the microtextural relationships and determined FIA trends from garnet, staurolite, kyanite and plagioclase porphyroblasts within the Wissahicken formation, Maryland. The succession of FIA sets showed consistent relative prograde mineral growth sequence of garnet-staurolite/ kyanite/ plagioclase-sillimanite according to their textural relationships (Fig. 5). As shown in Fig. 5, older FIA sets were recorded in garnet and staurolite porphyroblasts while kyanite, plagioclase porphyroblasts recorded much younger FIA sets. Thus, FIAs provide a powerful tool to distinguish different growth periods for porphyroblasts.

\subsection{Reconstruction and Correlation of Deformation History}

FIA data recorded around oroclines (e.g., the Pennsylvania orocline in the Appalachians, Yeh 2002; the Kimberly arc, Bell and Mares 1999) reveal a striking consistency of FIA trends even though the regions have undergone multiple-deformation events. This suggests that the same succession of FIA trends remains consistent across large areas and that the distribution and succession of FIA trends may allow one to distinguish and correlate multiple phases of metamorphism and deformation along the full length of orogens (Bell et al. 1995, 1998; Bell and Mares 1999; Yeh 2002).

\subsection{Implications for Plate Tectonic History}

Several studies have suggested that one of the most important applications of the FIA technique might be in its potential to identify the direction of relative plate motion during orogenesis (e.g., Bell et al. 1995). Near-orthogonal overprinting matrix foliations and inclusion trails are becoming increasingly recognized and documented from orogenic belts around the world (Hayward 1992; Johnson 1999a, b; Davis 1993; Aerden 1994; Roo and Stael 1994; Bell and Hickey 1998; Yeh 2002). If the porphyroblasts have not rotated, inclusion trail geometries can only be explained by a succession of subvertical and subhorizontal near-orthogonal overprinting foliations (Bell and Johnson 1989; Bell et al. 1997, 1998) This pattern is interpreted as reflecting horizontal compression and gravitational loading at the macroscopic scale during orogenesis (Bell and Johnson 1989; Hayward 1992; Johnson 1999a), with sub-vertical shortening or collapse occurring when a build up of gravitational potential energy, due to 
Table 1. Timing relationship of each FIA sets observed from Multi-FIAs recorded from garnet porphyroblasts around Beltimore gneiss domes, Maryland, USA. No FIAs are older than set I as all of them are core FIAs, making set I FIA as the oldest set. Similarly, no FIAs are younger than set VIII FIA as all of them are rim FIAs, making set VIII the youngest. All FIA sets with smaller set number is always older than FIA sets with larger number except one set II FIA is younger than set III. Data modified from Yeh (2002).

(Younger than)

\begin{tabular}{|c|c|c|c|c|c|c|c|c|}
\hline $\begin{array}{c}\text { FIA set } \\
\text { Range } \\
\left(^{\circ}\right)\end{array}$ & $\begin{array}{c}\mathrm{I} \\
30-50\end{array}$ & $\begin{array}{c}\Pi \\
10-30\end{array}$ & $\begin{array}{c}\text { III } \\
160-190\end{array}$ & $\begin{array}{c}\text { IV } \\
50-100\end{array}$ & $\begin{array}{c}\mathrm{V} \\
100-130\end{array}$ & $\begin{array}{c}\text { VI } \\
130-160\end{array}$ & $\begin{array}{c}\text { VII } \\
160-200\end{array}$ & $\begin{array}{c}\text { VIII } \\
70-110\end{array}$ \\
\hline I & 0 & 0 & 3 & 2 & 0 & 1 & 1 & 0 \\
\hline II & 0 & 0 & 5 & 5 & 2 & 4 & 0 & 0 \\
\hline III & 0 & 1 & 3 & 6 & 4 & 3 & 6 & 1 \\
\hline IV & 0 & 0 & 0 & 0 & 1 & 0 & 0 & 1 \\
\hline V & 0 & 0 & 0 & 0 & 0 & 3 & 3 & 1 \\
\hline VI & 0 & 0 & 0 & 0 & 0 & 0 & 5 & 0 \\
\hline VII & 0 & 0 & 0 & 0 & 0 & 0 & 0 & 1 \\
\hline VIII & 0 & 0 & 0 & 0 & 0 & 0 & 0 & 0 \\
\hline
\end{tabular}

thickening of the crust, induces collapse and lateral extrusion (Bell and Johnson 1989; Aerden and Malavieille 1999). Hickey and Bell (2001) suggest the Appalachian orogen in southeast Vermont underwent cycles of thickening and collapse at a scale large enough to produce subhorizontal folds and foliations that overprint the Spring Hill synform. Similar cycles are suggested by the alternation of steep and shallow foliations within porphyroblast and matrix foliations of the Baltimore gneiss anticlines (Yeh 2002).

Based on Bell and Johnson's (1989) orogenic model, the direction of horizontal bulk shortening preserved through FIAs may directly reflects the direction of relative plate motion that caused orogenesis (Bell et al. 1995, 1997, 1998). Similar FIA trends and time sequences could be observed from different regions along an orogen that have experienced the same orogenic events regardless of their local structural and metamorphic history. Such striking coincidence of FIA trend succession have been recorded across different regions of: Vermont (Bell et al. 1998, 2003), the Pelham Dome, Massachusetts (Kim 2000), the Bolton syncline, NW Connecticut (Hickey and Bell 1999), the Orange-Milford Belt, SW Connecticut (Newman 2001), the Baltimore-Washington Anticlinorium, E. Maryland (Yeh 2002) and the Canton Schist, Georgia (Stallard 1999) along the Appalachian orogen belt (Fig. 6). Furthermore, the consistency of isotopic ages for the peak of metamorphism with FIA succession across the arc (Fig. 6; Armstrong et al. 1992; Coleman et al. 1997; Lanzirotti et al. 1995; Glover et al. 1983; Ratcliffe et al. 1992; Sinha et al. 1997) suggests that these FIAs may reflect a succession of 
directions of bulk shortening, and hence changes in directions of relative plate motion, that accompanied the tectonic development of the orogen. Significantly, FIAs enable correlation of structural and metamorphic histories between rocks that have undergone completely different P-T paths across a large region, or across younger shear zones on which there has been large vertical displacements (Bell and Mares 1999). Incorporation of FIA sequences with the established geochronological data and metamorphic framework from region to region as described above had established a possible tectonic sequence for the Appalachians. The FIA sequence derived from this study appears to reveal a new method for correlating the timing of deformation and metamorphic events along the Appalachian Orogen (Bell et al. 1998, 2003; Kim 2000; Newman 2001; Stallard 1999; Yeh 2002), especially where the effects of 2 orogenies need to be distinguished.

\section{DISCUSSION}

\subsection{Significance of FIA}

It has been proposed that complex curvilinear $\mathrm{S}_{\mathrm{i}}$ geometries preserved within porphyroblasts are the result of successive overprinting matrix crenulations against porphyroblast rims that were subsequently included within the growing porphyroblast. If this is correct, FIAs within porphyroblasts of the overprinting included fabrics should form perpendicular to the direction of bulk shortening (Bell et al. 1995, 1998). Matrix fabrics that are not overgrown and preserved within porphyroblasts may be rotated or obliterated by subsequent deformation and/or metamorphism associated with continued deformation. Provided the porphyroblasts preserving the $\mathrm{S}_{\mathrm{i}}$ geometries remain stable under the varying P-T conditions associated with tectonism, exhumation and uplift, they should preserve evidence of earlier deformations that are destroyed in the matrix. The relative timing and spatial distribution of FIAs provide a means to differentiate stages of porphyroblast growth in a manner not previously possible. The orientation of different FIA generations also places constraints on the kinematic (rotational) behaviour of porphyroblasts during non-coaxial ductile deformation. Observed changes in FIA orientation with time appear to record changes in the orientation of the kinematic reference frame. However, the effects of separation head of continent during collision and/or oblique collision would produced different strain regimes across a region, care must be taken when correlating FIA successions across a large area.

\subsection{Rotation vs Non-rotation of Porphyroblasts}

Despite the enormous attention drown towards the study of porphyroblast microstructurals, the interpretations are strongly polarized between structural geologists for the past two decades (e.g., Bell et al. 1992a, b, c; Passchier et al. 1992). One of the biggest dilemmas has been whether porphyroblasts rotated relative to geographic co-ordinates during deformation. Since the turn of the century, geologists have generally considered that rigid objects rotate relative to geographic co-ordinates during non-coaxial ductile deformation (Jeffery 1992). This "paradigm" was not questioned nor tested in naturally deformed rocks till a decade ago (Bell and 
a)

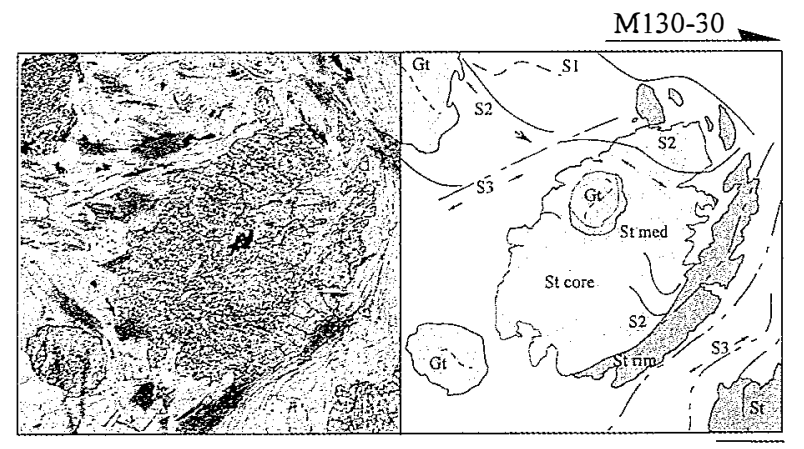

b)

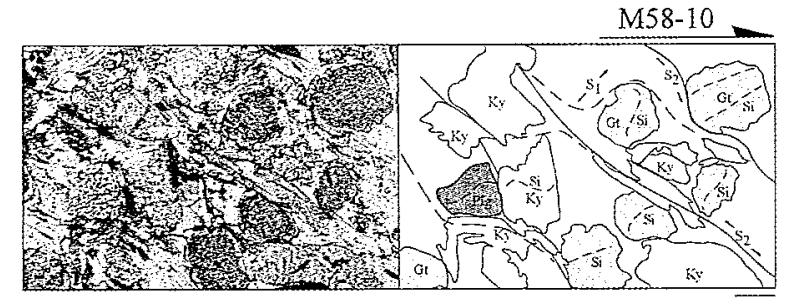

c)

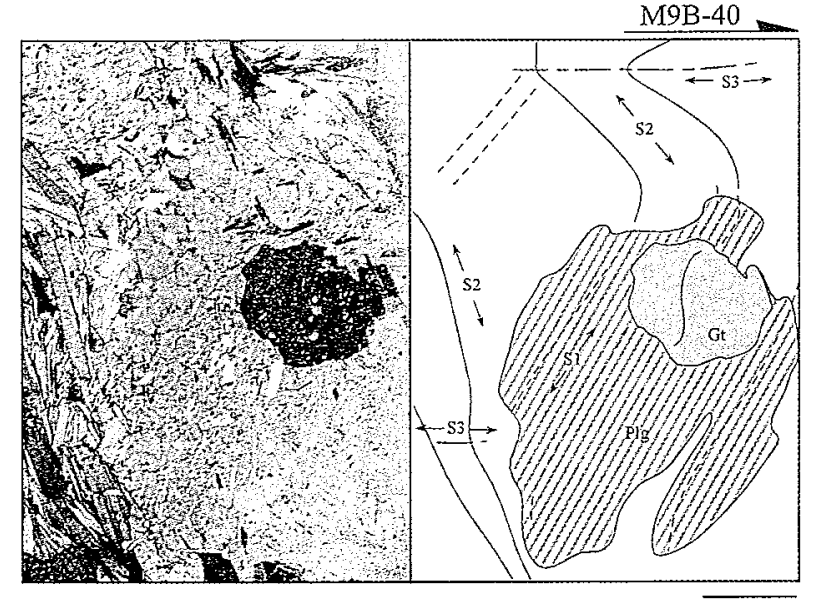

d)
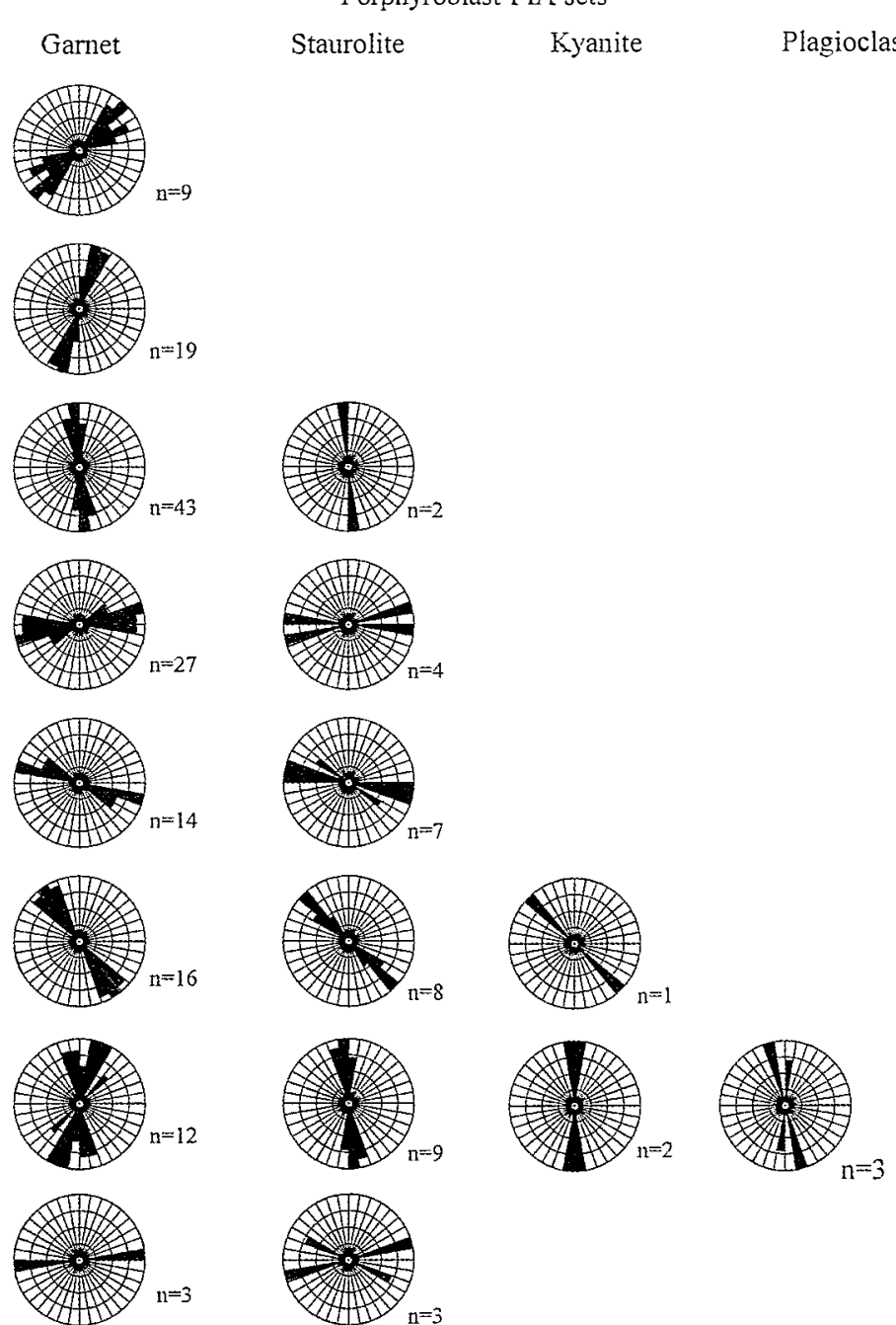
Fig. 5. Microphotographs and accompanying line diagrams and rose diagrams showing the textural relation and relative succession of FIA sets between garnet (Gt), staurolite (St), Kyanite (Ky) and Plagioclase (Plg) porphyroblasts. All microphotographs are taken from vertical thin sections with arrow indicating strikes, partially crossed polarized light. The scale bars are $2 \mathrm{~mm}$ in length. (a) Garnet porphyroblasts are medium grey in color, containing inclusion free rims and slightly curved inclusion trails defined by fine grained quartz and ilmenite. Staurolite with garnet inclusion indicates the late grow nature of staurolite compared to garnet. Up to three period of growth can be distinguished from staurolite, which are marked by various shades of gray. No trails can be distinguished in staurolite core. Median inclusion trails are continuous with S2 matrix foliation, truncated by the rim inclusion trails continuous with S3. (b) Garnet porphyroblasts contain inclusion free rims and are in contact with kyanite porphyroblasts, suggesting earlier growth of garnet porphyroblasts compared to the kyanite porphyroblasts. Plagioclase contains S1 parallel inclusion trails truncated by the $\mathrm{S} 2$ matrix foliation suggesting syn- or post $\mathrm{S} 1$ growth. Multiple growth stages of kyanite are suggested by different styles of inclusion trails and S2 parallel mineral shapes. (c) Plagioclase porphyroblasts contain garnet inclusions and inclusion trails continuous with $\mathrm{S} 1$ in the matrix that is truncated by $\mathrm{S} 2$. The garnet porphyroblast contains gently curved inclusion trails truncated by inclusion trails in plagioclase suggesting earlier growth of garnet than plagioclase. (d) Equal area (radii = square root of frequency) rose diagrams with a $10^{\circ}$ class interval showing the relative succession of FIA sets measured from garnet, staurolite, kyanite and plagioclase porphyroblasts. Modified from Yeh (2002).

Johnson 1990; Hayward 1990; Aerden 1994; Hickey and Bell 1999). Fyson (1980) demonstrated non-rotation of porphyroblast with respect to geographic co-ordinates using consistently oriented inclusion trails for elongated biotite porphyroblasts across the $25 \mathrm{~km}$ wavelength Cleft Lake fold in Canada. Examples of consistency in the orientation of porphyroblast $\mathrm{S}_{\mathrm{i}}$ foliations across large areas were noted from many regions (Otago schists in New Zealand: Johnson 1990; Lys-Caillaouas Massif, Pyrenees: Aerden 1994; Cordillera Betica in Spain, Bell et al. 1995; Quinlin orogen in China, Bell and Chen 2002). Furthermore, the classical ìrotationalî spiral or snowball inclusion trail geometries in porphyroblasts can also be modeled by non-rotation (Bell et al. 1992a, b, c; Aerden 1994; Lee 2000), or both rotation and nonrotation (Ilg and Karlstrom 2000) of porphyroblasts relative to geographical co-ordinance with multiple truncations.

With the development of FIA technique, numerous FIA data had been collected along the Appalachians (Bell et al. 1998; Hickey and Bell 1999; Kim 2000; Newman 2001; Stallard 1999; Yeh 2002), Alps (Bell et al. 1995), and Goesan belts, South Korea (Lee 2000). If porphyroblasts had rotated during non-coaxial deformation, completely random FIA trends 
a) Spring Hill Synform region, Vermont

U-Pb zircon age: 385-395

$\mathrm{Ma}$

b) Pelham Dome,

NC Massachusetts

U-Pb zircon age:

Acadian, 290-300 Ma

c) Bronson Hill syncline, NW Connecticut

U-Pb monazite age: $305-$

$307 \mathrm{Ma}$

d) Orange-Milford Belt SW Connecticut

U-Pb zircon age: 375 $420 \mathrm{Ma}$

e) B-W Anticlinorium E Maryland

U-Pb zircon age: $420-470$

$\mathrm{Ma}, 290 \mathrm{Ma}$
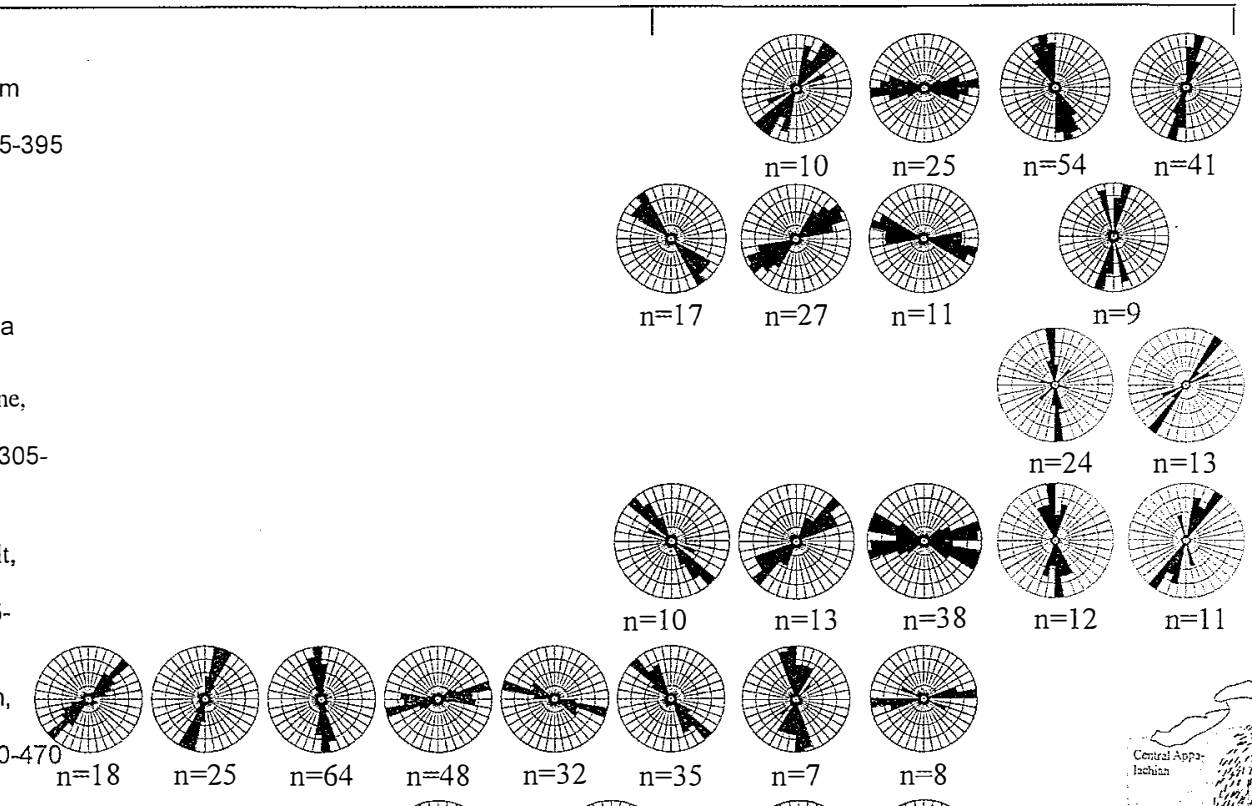

$\mathrm{n}=54$

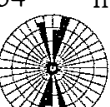

$\mathrm{n}=27$

$\mathrm{n}=11$

$\mathrm{n}=9$

f) Canton Schist, Geor-

Uia $\mathrm{Pb}$ zircon age: 400

$430 \mathrm{Ma}$
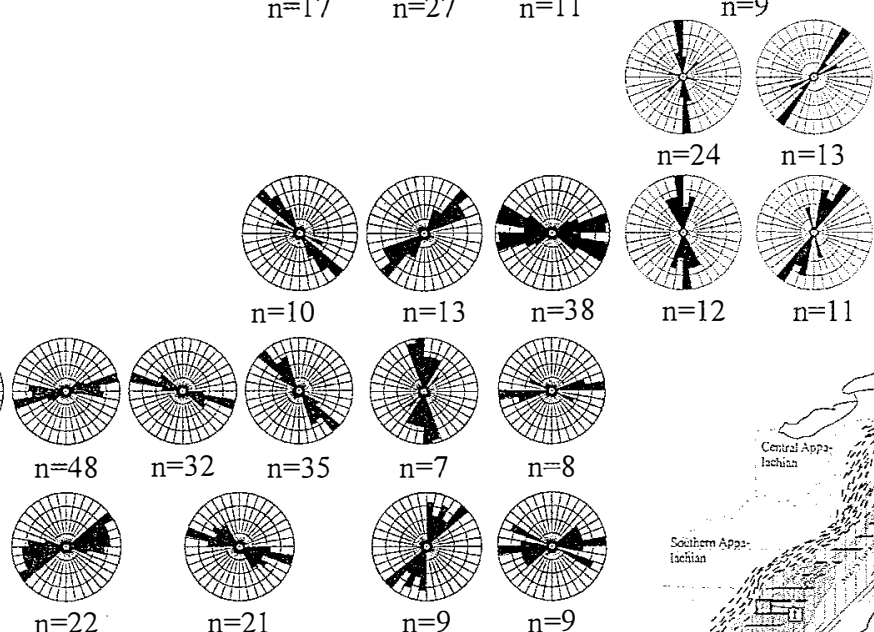

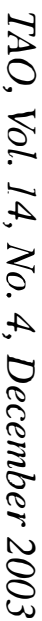

Fig. 6. Proposed full sequence of FIA succession correlated between the five regions within the Appalachians. Regions within the northern Appalachians (Vermont, Massachusetts and Connecticut) indicated the FIA succession that resulted from the Acadian orogeny. Regions within central and southern Appalachians (Maryland and Georgia) indicated the FIA succession that resulted from the Taconian orogeny with an Acadian overprint. Modified from Yeh (2002). 
and successions would eventuate as each FIA was rotated about the next and so on. However, the FIA trends recorded from many studies (e.g., Arden 1994; Bell et al. 1998; Bell and Hickey 1998; Johnson 1990) suggested otherwise. Although the spread in FIA trends for one set range from $20^{\circ}$ to $50^{\circ}$, many studies (e.g., along the Appalachians: Kim 2000; Newman 2001; Stallard 1999; Yeh 2002) had shown that the FIA trends for several successive sets remained remarkably consistent. This strongly suggests that porphyroblasts containing successive sets of FIAs were not rotated during younger periods of deformation.

\section{CONCLUSION}

The FIA technique allows 3-demensional determination and measurement of intersection lineation or inflection axes between $\mathrm{S}_{\mathrm{i}}$ within porphyroblasts. This relatively new microstructural analysis approach provides a new way of correlating in great detail deformation and metamorphism. With the unique multimodal character and temporal succession recorded by porphyroblasts with multiple growth episodes, FIAs can be used to reconstruct and correlate deformation history with bulk shortening direction over large-scale areas. Furthermore, FIAs could be useful in examining the effects of ancient plate motions and hence reconstruct the tectonic evolutions.

Acknowledgements I thank Tim Bell, T. Y. Lee, E. C. Yeh, and the two anonymous reviewers for providing comments and suggestions on the manuscript. The SAMRI research group of the James Cook University, Australia is acknowledged for providing me the great opportunity to learn about FIA and microstructural geology. Cameron Huddlestone-Holmes is thanked for helpful discussion on the new developing X-ray tomography technique. The National Taiwan Normal University and the National Science Council (NSC 92-2811-M-003-010) are also acknowledged for their financial and equipment support.

\section{REFFERENCES}

Aerden, D. G., 1994: Kinematics of orogenic collapse in the variscan pyrenees deduced from microstructures in porphyroblastic rocks from the Lys-Caillaouas Massif: Late Orogenic extension. Tectonophysics, 238/1, 139-60.

Aerden, D. G., 1995: Porphyroblast non-rotation during crustal extension in the Variscan Lys-Caillaouas Massif, Pyrenees. J. Stru. Geo, 17, 709-725.

Aerden, D. G., and G. A. M. Malavieille, 1999: Origin of a large-scale fold nappe in the Montagne Noire, Variscan Belt, France. J. Stru. Geo., 21, 1321-33.

Aerden D. G., 2003: Preferred orientation of planar microstructures determined via statistical best-fit of measured intersection-lines; the "FitPitch" computer program. J. Stru. Geo., 25/6, 923-934.

Armstrong, T. R., R. J. Tracy, and W. E. Hames, 1992: Contrasting styles of Taconian, eastern Acadian and western Acadian metamorphism, central and western: New Metamorphic styles in young and ancient orogenic belts. J. Meta. Geo., 10(3), 415-426. 
Bell, T. H., 1981: Foliation development: the contribution, geometry and significance of progressive bulk inhomogeneous shortening. Tectonophysics, 75, 273-296.

Bell, T. H., and S. E. Johnson, 1989: Porphyroblast inclusion trails: the key to orogenesis. $J$. Meta. Geo., 10, 99-124.

Bell, T. H., and S. E. Johnson, 1990: Rotation of relatively large rigid objects during ductile deformation: well established fact or intuitive prejudice? Australian J. Earth Sci., 37, 441-46.

Bell, T. H., S. E. Johnson, B. David, A. Forde, N. Hayward, and C. Wilkins, 1992a: Porphyroblast inclusion-trail orientation data: Eppure Non Son Girate?! J. Meta. Geo., 10, 295-307.

Bell, T. H., A Forde, and N. Hayward, 1992b: do smoothly curved, spiral-shaped inclusion trails signify porphyroblast rotation? Geology, 10, 59-62.

Bell, T. H., A. Ford, and N. Hayward, 1992c: Do smoothly curved, spiral-shaped inclusion trails signify porphyroblast rotation? reply. Geology, 10, 55-56.

Bell, T. H., A. Ford, and J. Wang, 1995: A new indicator of movement direction during orogenesis: measurement technique and Application to the Alps. Terra Nova, 7, 500508.

Bell, T. H., and K. A. Hickey, 1997: Distribution of pre-folding linear indicators of movement direction around the Spring Hill Synform, Vermont significance for mechanism of folding in this portion of the Appalachians. Tectonophysics, 274, 275-94.

Bell, T. H., and K. A. Hickey, 1998: Multiple deformations with successive subvertical and subhorizontal axial planes in the Mount Isa region their impact on geometric development and significance for mineralization and exploration. Econ. Geo., 93, 1369-89.

Bell, T. H., K. A. Hickey, and J. G. Upton, 1998: Distinguishing and correlating multiple phases of metamorphism across a multiply deformed region using the axes of spiral, staircase and sigmoidal inclusion trails in garnet. J. Meta. Geo., 16, 767-794.

Bell, T. H., and V. M. Mares, 1999: Correlating deformation and metamorphism around orogenic arcs. Ame. Min., 84, 1727-40.

Bell, T. H., and A. Chen, 2002: The development of spiral-shaped inclusion trails during multiple metamorphism and folding. J. Meta. Geo., 20/4, 397-412.

Bell, T. H., and P. W. Welch, 2002: Prolonged Acadian Orogenesis: Revelations from FIA Controlled Monazite Dating of Foliations in Porphyroblasts and Matrix. American J. Sci., 302, 549-581.

Bell, T. H., A. P. Ham, and K. A. Hickey, 2003: Early formed regional antiforms and synforms that fold younger matrix schistosities: their effect on sites of mineral growth. Tectonophysics, in press.

Coleman, D. S., J. M. Bartley, J. D. Walker, D. E. Price, and A. M. Friedrich, 1997: Extensional faulting, footwall deformation and plutonism in the Mineral Mountains, southern Sevier Desert Mesozoic to recent Geology of Utah. Geology Studies, 42, 203-233.

Davis, B. K., 1993: Mechanism of emplacement of Cannibal Creek Granite with special reference to timing and deformation history of the Aureole. Tectonophysics, 242, 293311.

Davis, B. K., 1995: Regional-scale foliation reactivation and re-use during formation of a 
macroscopic fold in the Robertson River Metamorphics, North Queensland, Australia. Tectonophysics, 242, 293-311.

Forde, A., and T. H. Bell, 1993: The rotation of garnet porphyroblasts around a single fold, Lukmanier Pass, Central Alps: discussion. J. Stru. Geo., 15/11, 1365-68.

Freedman, L. S., 1981: Watson's U2N statistic for a discrete distribution. Biometrics, 68, 708-711.

Fyson, W. K., 1980: Fold favrics and emplacement of an Archean granulite pluton Cleft Lake, Northwest Territories. Canadian J. Earth Sci., 17, 325-332.

Glover, L., A. Speer, G. S. Russell, and S. Farrar, 1983: Ages of regional Metamorphism and Ductile Deformation in the Central and Southern Appalachians. Lithos, 16, 223-43.

Hayward, N., 1990: Determination of early fold axis orientations in multiply deformed rocks using porphyroblast inclusion trails. Tectonophysics, 179, 353-69.

Hayward, N., 1992. Microstructural analysis of the classical spiral garnet porphyroblasts of south-east Vermont: evidence for non-rotation. J. Meta. Geo., 10, 567-587.

Hickey, K., and T. Bell, 1999: Behavior of rigid objects during deformation and metamorphism; a test using schists from the Bolton Syncline, Connecticut, USA. J. Meta. Geo., 17/2, 211-28.

Hickey, K., and T. Bell, 2001: Timing fold development in multideformed terrains: the role of orthogonally overprinting foliations. GSA Bulletin, 113/10, 1282-1289.

Ilg, B. R., and K. E. Karlstrom, 2000: Porphyroblast inclusion trail geometries in the Grand Canyon; evidence for non-rotation and rotation? J. Stru. Geo., 22/2, 231-243.

Jeffery, G. B., 1992: The motion of ellipsoidal particles immersed in a viscous fluid. Proc. Royal Soci. London, A102, 161-179.

Johnson, S. E., 1990: Lack of porphyroblast rotation in the Otago Schists, New Zealand: implications for crenulation cleavage development, folding and deformation partitioning. J. Meta. Geo., 8, 13-30.

Johnson, S. E., 1993a: Unraveling the spirals: a serial thin-section study and three-dimensional computer-aided reconstruction of spiral-shaped inclusion trails in garnet porphyroblasts. J. Meta. Geo., 11, 621-34.

Johnson, S. E., 1993b: Testing models for the development of spiral-shaped inclusion trails in garnet porphyroblasts: to rotate or not to rotate, that is the question. J. Meta. Geo., 11, 635-59.

Johnson, S. E., and M. L. Williams, 1998: Determining finite longitudinal strains from oppositely-concave microfolds in and around porphyroblasts: a new quantitative method. $J$. Stru. Geo., 20/11, 1521-30.

Johnson, S. E., 1999a: Near-orthogonal foliation development in orogens: meaningless complexity, or reflection of fundamental dynamic processes? J. Stru. Geo., 21, 118387.

Johnson, S. E., 1999b: Porphyroblast microstructures: a review of current and future trends. Ame. Min., 84, 1711-26.

Kim, Hyeong Soo, 2000: Structural And Metamorphic Evolution of The Northern Appalachian Orogenic Belt in North-central Massachusetts, USA. Ph.D. dissertation. James Cook University, Australia. 
King, M., 1994: Fisheries Biology, Assessment and Management, Oxford, England, pp. 301306.

Lanzirotti, A., G. N. Hanson, and R. D. Smith, 1995: The Orange-Milford Belt of southwestern Connecticut; identifying unique crustal packages in New England using combined geochemistry, geochronology, and petrology. Geological Society of America, Northeastern Section, 30th annual meeting Abstracts with Programs, 27/1, 63.

Lee, H., 2000: Significance of systematic changes in crenulation asymmetries within metasediments across the Ogcheon Supergroup in the Goesan area, southern Kaorea. Geosci. J., 4/2, 115-134.

Newman, R. L., 2001: Inter-relationships Between Deformation and Metamorphism During Acadian orogenesis SW Connecticut. Ph.D. dissertation. James Cook University, Australia.

Passchier, C. W., R. A. J. Trouw, H. J. Zwart, and R. L. M. Vissers, 1992: Porphyroblast rotation: Eppur Si Muove? J. Meta. Geo., 10, 283-94.

Powell, C., and R. H. Vernon, 1979: Growth and rotation history of garnet porphyroblasts with inclusion spirals in a Karakoram Schist. Tectonophysics, 54, 25-43.

Ratcliffe, N. M., T. R. Armstrong, and R. J. Tracy, 1992: Tectonic-cover basement relations and metamorphic conditions of formation of the Sadawga, Rayponda and Athens domes, southern Vermont. Guidebook for field trips in the Connecticut Valley region of Massachusetts and adjacent states, Contribution - Geology Department, University of Massachusetts, 66, pp. 257-290.

Roo, de J. A., and C. R. van Stael, 1994: Transpression and extensional collapse: steep belts and flat belts in the Appalachian central mobile belt, Northern New Brunswick, Canada. GSA Bulletin, 106, 541-52.

Rosenfeld, J. L., 1968: Garnet rotations due to the major Paleozoic deformations in Southeast Vermont. in Studies of Appalachian Geology (ed. by E. Zan, W. S. White, J. B. Hadley, and J. B. Thompson), John Wiley and Sons, Inc. USA, pp. 185-202.

Rosenfeld, J. L., 1970: Rotated garnets in metamorphic rocks, GSA Special Paper, 129, 1105.

Rosenfeld, J. L., J. N. Christensen, and D. J. DePaolo, 1988: Snowball garnets revisited, southeastern Vermont. New England intercollegiate geological conference 80th annual meeting. Guidebook for field trips in southwestern New Hampshire, southeastern Vermont, and north-central Massachusetts, Geological Society, pp. 223-240.

Sinha, A. K., B. Hanan, and D. M. Wayne, 1997: Igneous and metamorphic U-Pb zircon ages from the Baltimore mafic complex, Maryland Piedmont. GSA Memoir, 191, 275-86.

Stallard, A. R., 1999: Porphyroblast-matrix Microstructures And Garnet Compositional Zoning: Constraints on Foliation Development Fold Mechanisms and Porphyroblast Growth. $\mathrm{Ph}$ D. dissertation. James Cook University, Australia.

Stallard, A., and K. Hickey, 2001: Shear zone vs folding origin for spiral inclusion trails in the Canton Schist. J. Stru. Geo., 23/12, 1845-1864.

Upton, G. J., and B. Fingleton, 1989: Spatial Data Analysis by Example, 2, Wiley and Sons, New York.

Welch, P., 2003, Integration of Structure and Metamorphism Processes in rocks from the 
New England Appalachian [Ph.D. dissertation]: Australia, James Cook University.

Williams, M. L., 1994: Sigmoidal inclusion trails, punctuated fabric development and interactions between metamorphism and deformation. J. Meta. Geo., 12, 1-21.

Williams, P. F., and D. Jiang, 1999: Rotation garnets. J. Meta. Geo., 17/4, 367-378.

Yeh, M. W., 2002: Structural and Tectonic History of the Central Appalachians, USA, [Ph.D. dissertation]: Australia, James Cook University. 